\title{
Four Decades of Military Posttraumatic Stress: Protocol for a Meta-analysis and Systematic Review of Treatment Approaches and Efficacy
}

Jenny J W Liu ${ }^{1,2}$, PhD; Anthony Nazarov ${ }^{1,2,3}, \mathrm{PhD}$; Bethany Easterbrook ${ }^{1,3}$, MSc; Rachel A Plouffe $^{1,2}$, PhD; Tri Le ${ }^{1}$, BHSc; Callista Forchuk ${ }^{1}$, MSc; Alec Brandwood ${ }^{1}$, BHSc; Kate St Cyr ${ }^{1,4}$, MSc; Edouard Auger ${ }^{5,6}$, MD, FRCPC; Ken Balderson $^{2,7}$, MD, CM, FRCPC; Mathieu Bilodeau ${ }^{5,6}$, MSc, MD, FRCPC; Amer M Burhan ${ }^{8,9}$, MBChB, MSc, FRCPC; Murray W Enns ${ }^{10,11}$, MD, FRCPC; Patrick Smith ${ }^{12}$, PhD; Fardous Hosseiny ${ }^{12}$, MSc; Gabrielle Dupuis ${ }^{12}$, MSc; Maya Roth $^{7,13}, \mathrm{PhD}$, CPsych; Natalie Mota ${ }^{14}, \mathrm{PhD}$; Vicky Lavoie ${ }^{5}$, PhD; J Don Richardson ${ }^{1,2,15}$, MD, FRCPC

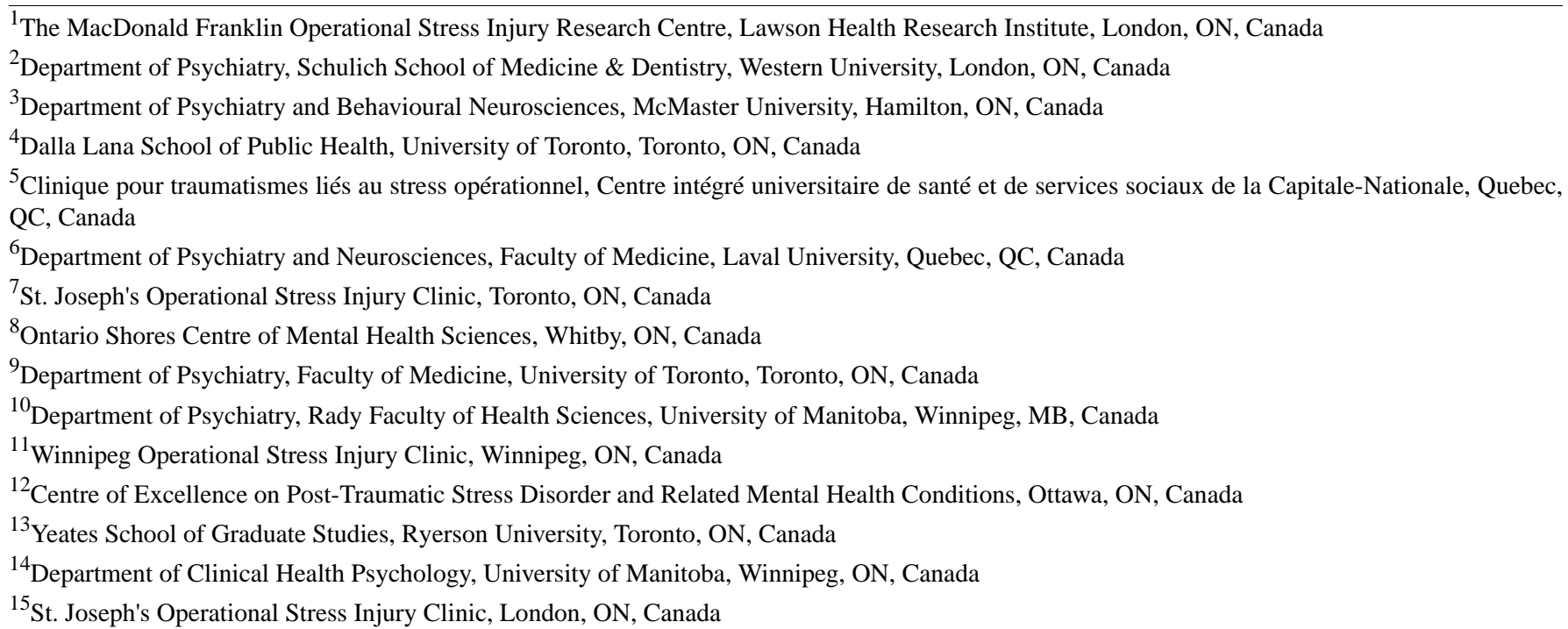

\section{Corresponding Author:}

Jenny J W Liu, PhD

The MacDonald Franklin Operational Stress Injury Research Centre

Lawson Health Research Institute

Parkwood Institute Research, Mental Health Building

550 Wellington Road, Rm F4-367

London, ON, N6C 0A7

Canada

Phone: 15196854292 ext 48211

Email: jenny.liu@sjhc.london.on.ca

\section{Abstract}

Background: Over $85 \%$ of active members of the Canadian Armed Forces have been exposed to potentially traumatic events linked to the development of posttraumatic stress disorder (PTSD). At the time of transition to civilian life, as high as 1 in 8 veterans may be diagnosed with PTSD. Given the high prevalence of PTSD in military and veteran populations, the provision of effective treatment considering their unique challenges and experiences is critical for mental health support and the well-being of these populations.

Objective: This paper presents the protocol for a meta-analysis and systematic review that will examine the effectiveness of treatment approaches for military-related PTSD.

Methods: This PROSPERO-preregistered meta-analysis is being conducted in accordance with the PRISMA (Preferred Reporting Items for Systematic Reviews and Meta-Analyses) and Cochrane guidelines. A comprehensive search of the literature was 
conducted using the databases PsycInfo, Medline, Embase, CINAHL, and ProQuest Dissertation \& Theses. Effect sizes will be computed based on changes in PTSD symptom scores over time across studies using validated PTSD scales. A multilevel meta-analysis will examine the overall effects, between-study effects, and within-study effects of available evidence for PTSD treatments in military populations. Effect sizes will be compared between pharmacotherapeutic, psychotherapeutic, and alternative/emerging treatment interventions. Finally, meta-regression and subgroup analyses will explore the moderating roles of clinical characteristics (eg, PTSD symptom clusters), treatment approaches (eg, therapeutic orientations in psychotherapy and alternative therapies and classifications of drugs in pharmacotherapy), as well as treatment characteristics (eg, length of intervention) on treatment outcomes.

Results: The literature search was completed on April 14, 2021. After the removal of duplicates, a total of 12,002 studies were screened for inclusion. As of July 2021, title and abstract screening has been completed, with 1469 out of 12,002 (12.23\%) studies included for full-text review. Full review is expected to be completed in the summer of 2021, with initial results expected for publication by early winter of 2021 .

Conclusions: This meta-analysis will provide information on the current state of evidence on the efficacy and effectiveness of various treatment approaches for military-related PTSD and identify factors that may influence treatment outcomes. The results will inform clinical decision-making for service providers and service users. Finally, the findings will provide insights into future treatment development and practice recommendations to better support the well-being of military and veteran populations.

Trial Registration: PROSPERO CRD42021245754; https://tinyurl.com/y9u57c59

International Registered Report Identifier (IRRID): DERR1-10.2196/33151

(JMIR Res Protoc 2021;10(10):e33151) doi: 10.2196/33151

\section{KEYWORDS}

military personnel; psychotherapy; pharmacotherapy; stress disorders; posttraumatic; meta-analysis; systematic review; therapy; stress; disorder; posttraumatic stress disorder; review; treatment; efficacy; military; Canada; veteran

\section{Introduction}

\section{Background}

Over $85 \%$ of active members of the Canadian Armed Forces have reported exposure to potentially traumatic events [1], and studies estimate that between $7.5 \%$ and $12.9 \%$ of veterans are diagnosed with posttraumatic stress disorder (PTSD) on return to civilian life [2,3]. Military-related PTSD may differ from PTSD experienced by civilians [4]. The risk factors, etiology, and prognosis of military-related PTSD are associated with military service, deployment stressors, and unique potentially traumatic events. These events include experiences of combat, moral injury, military sexual trauma, and the LGBTQ Purge $[2,5,6]$. As a result, PTSD treatment for military and veteran populations may differ in effectiveness from that for nonmilitary populations. Studies have shown that outcomes of both pharmacotherapy and psychotherapy for military-related PTSD have a smaller effect size than those for civilian-related PTSD; military members and veterans have reported poorer response to treatments than civilians [7-9]. In a recent review, Coventry et al [10] noted that while trauma-focused therapies were particularly effective in treating PTSD, the effect was less for military- and veteran-related PTSD.

Given the prevalence of PTSD and the uniqueness of the PTSD experience in military populations, the provision of effective treatment and support is of utmost importance. However, ambiguities and heterogeneities in reports of effectiveness are challenging for service providers [11]. Recent reviews highlight the lack of consensus regarding the trajectory of PTSD, the diversity of approaches in the diagnosis and treatment of PTSD, and the inconsistencies in defining response to PTSD treatments as problematic [10,12-14]. In addition, novel empirical evidence has also underscored service users participating in the treatment decision-making process as additional important determinants of treatment outcomes [4]. Provision of timely, appropriate, and effective treatments and support that are aligned across organizations, service providers, and service users is critical to the well-being of military personnel and veterans. Thus, we aim to provide an overview of the effectiveness of existing treatment options for military-related PTSD.

\section{Treating Military-Related PTSD}

Since the classification of PTSD as a mental disorder in 1980, treatments have evolved to encompass a diversity of approaches, targeting a multitude of symptomology, functioning, and pathways. As a result, clinicians and mental health service providers face the difficult challenge of developing a treatment plan for those diagnosed with PTSD. Current evidence-based treatments can be classified into two categories: psychologically based and pharmacologically based treatments.

The majority of the empirically supported psychological treatments for PTSD fall within the cognitive behavioral therapy framework. Examples of these treatments include cognitive processing therapy [15], trauma-focused cognitive behavioral therapy [16], and prolonged exposure [17]. Outside of the cognitive behavioral therapy framework, another empirically supported treatment for PTSD is eye movement desensitization and reprocessing [18]. In the military context, trauma-focused psychotherapies (prolonged exposure, cognitive processing therapy, and eye movement desensitization and reprocessing) are the most recommended approaches to treating PTSD [19]. These therapies focus on trauma-related negative cognitions and challenging situational and cognitive avoidance as well as on processing the meaning of the trauma. Together, prolonged exposure, cognitive processing therapy, and eye movement 
desensitization and reprocessing have shown to be most effective in ameliorating PTSD symptoms $[19,20]$. While much of the effectiveness of these treatments has been evaluated in individual therapy format, there is also increasing empirical support for administering these treatments-specifically cognitive processing therapy - in group format [21]. Some recent studies have also found selective interventions to be noninferior to some trauma-focused therapies, including interpersonal psychotherapy [22] and acceptance and commitment therapy [23].

Pharmacological treatment of PTSD involves the use of various psychotropic medications to target the core symptoms of PTSD, including intrusions, avoidance, negative alterations in cognition and mood, and alteration in arousal and reactivity [24]. As of July 2021, typical pharmacotherapies to treat PTSD include selective serotonin reuptake inhibitors, serotonin and norepinephrine reuptake inhibitors, atypical antipsychotics, $\beta$-blockers, and sleep medications (eg, $\alpha$-blockers, nabilone, hypnotics) [24]. Pharmacological treatments can be categorized by medication typologies, including antidepressants (eg, sertraline), antipsychotics (eg, risperidone), anticonvulsants (eg, topiramate), hypnotics (eg, zopiclone), and mood stabilizers (eg, lithium). In addition to classification according to drug typology, pharmacotherapy treatments can also be categorized by mechanisms of action.

Besides psychological and pharmacological treatments, there are a number of alternative and emerging treatments targeting different aspects of PTSD symptomology. These can include clinical treatments such as deep brain stimulation [25], noninvasive brain stimulation via repetitive transcranial magnetic stimulation, transcranial direct current stimulation [26], and neurofeedback [27]. Emerging therapies may also include cognitive-based conjoint therapy for PTSD [28], animal-assisted therapy [29], and yoga or mindfulness-based therapies [30]. In addition, given the high rates of comorbidities in individuals with PTSD, many approaches have incorporated the treatment of comorbidities to create new combination or adjunctive therapies for the treatment of PTSD [31]. These can include medication-enhanced psychotherapies such as methylenedioxymethamphetamine [32] and virtual reality-based treatments [33].

\section{Determinants of Treatment Approaches and Clinical Outcomes}

A number of review studies have summarized the effectiveness of various treatment approaches. A head-to-head review comparing psychological and pharmacological treatments of combat-related PTSD in 25 studies found that pharmacotherapeutic approaches were slightly more efficacious than psychotherapeutic approaches in ameliorating PTSD symptoms [34]. A network meta-analysis of treatments for PTSD and other mental health conditions stemming from complex trauma drew a contrasting conclusion from the results of 116 studies [10]. The findings suggested that pharmacological interventions were less effective than psychological interventions in the treatment of PTSD and associated functions such as sleep [10]. In addition to disparities across review findings, questions arise, including which factors, if any, influence the effectiveness of various treatment approaches, for whom are different interventions most effective, and what contextual factors, if any, can bolster the effectiveness of treatment approaches for this unique population.

Furthermore, additional effort is needed to expand the scope of reviews. Many reviews included evidence exclusively from randomized controlled trials that often used monotherapies or exclusion criteria [35]. However, the clear-cut criteria applied in research share little overlap with the complexities of real-life practices and experiences of diagnosing and treating PTSD in military and veteran populations. Treatment providers contend with complexities of patient characteristics (eg, chronicity and type of trauma), clinical characteristics of PTSD (eg, symptom clusters, prior treatment or use of medications, and comorbidities), and treatment characteristics (eg, length of treatment, type of treatment and augmentation [13], add-on, and adjunctive treatments) when making treatment-related decisions. In addition, treatment planning is often conducted with patient engagement and feedback in mind [36], and may involve many parallel processes with different health and mental health providers.

\section{Aims and Objectives}

Through a multilevel meta-analytic model, this meta-analysis and systematic review will review the state of evidence on existing treatment options for military-related PTSD and their effectiveness via a preregistered meta-analysis and systematic review. The meta-analysis will serve as a comprehensive scan of the literature while discriminating between effective and ineffective approaches based on considerations of clinical characteristics, treatment characteristics, and individual differences. The systematic review will evaluate the quality of the evidence and examine treatment fidelity, study rigor, and certainty of evidence. Protocols for the meta-analysis and systematic review were developed following the PRISMA (Preferred Reporting Items for Systematic Reviews and Meta-Analyses) guidelines and preregistered on PROSPERO to ensure transparency and replicability [37].

\section{Methods}

\section{Search Strategy}

The literature search was conducted using multiple databases (PsycINFO, PubMed/Medline, Embase, CINAHL, and ProQuest Dissertation \& Theses) on April 14, 2021, with a date restriction of 1980. The date restriction represents the first issue of the Diagnostic and Statistical Manual of Mental Disorders (DSM) III, in which PTSD was officially defined as a distinct diagnosis. In addition to these exploratory databases, we also used PTSDpubs, the JBI Database of Systematic Reviews and Implementation Report, and the Cochrane Library; hand searched for relevant articles via bibliographies; and used known author contact to search for additional titles for potential inclusion.

\section{Eligibility Criteria}

The following criteria were considered for inclusion in the study: (1) adults; (2) military personnel or veterans; (3) individuals with a current diagnosis of PTSD — with etiology due to military 
service (eg, combat-related PTSD)-under DSM-III, DSM-III-R, DSM-IV, DSM-IV-TR, DSM-5, or International Classification of Diseases criteria; (4) those with some form of incorporated treatment (psychotherapy, pharmacotherapy, alternatives); and (5) those in whom PTSD symptom change was measured via validated measures of PTSD severity (eg, PTSD Checklist for DSM-5). Exclusion criteria were (1) reviews and meta-analyses (though used for known author contact and search); (2) studies with nonadult populations (eg, children, nonhuman); (3) case studies with sample sizes of less than 5; (4) studies without a primary or secondary focus on PTSD in military and veteran populations; and (5) studies with no quantitative data (eg, protocols, corrections, commentaries, and qualitative studies).

\section{Comparison Groups}

While the overall effects of treatments for PTSD will be aggregated and analyzed, the current meta-analysis and systematic review will mainly explore heterogeneities in treatment approaches. These approaches can be broadly categorized as psychological treatments, pharmacological treatments, and alternative/emerging treatments. Psychological treatment is defined as any intervention grounded in the treatment of mental health through individual psychotherapy and delivered by registered mental health professionals. Pharmacological treatments are defined as any therapeutic approaches using prescribed medication(s) as the primary method of treatment. Alternative and emerging treatments include any alternatives and emerging treatments falling outside of the psychological and pharmacological treatment approaches (eg, equine therapy, deep brain stimulation, and ketamine-assisted therapy).

\section{Measures of Outcomes and Effect}

This review will assess changes in PTSD as measured from baseline to postintervention (psychotherapy, pharmacotherapy, or alternative/emerging treatment modality) using validated psychometric scales of PTSD. Measurements taken will report continuous values of PTSD symptomatology and can include the Clinician-Administered PTSD Scale for DSM-5 [38]; the PTSD Checklist for Military and Civilians for DSM-IV [39]; the PTSD Checklist for DSM-5 [40]; the Primary Care PTSD Screen for DSM-5 [41]; the Dissociative Subtype of PTSD Scale [42]; the Posttraumatic Diagnostic Scale for DSM-5 [43]; and the PTSD Symptom Scale [44].

Intervention effects will be examined using mean differences captured via continuous data, and aggregate data will be represented as Hedges $g$, calculated by the differences in means divided by the weighted pooled SD [45]. Hedges $g$ combines the SDs of experimental and control groups, resulting in single SD estimates of group differences [46]. Effect sizes will be interpreted based on the recommendation made by Ferguson [46]: Hedges $g$ of 0.41 for a minimum effect size representing a practically significant effect in social science, 1.15 for a moderate effect, and 2.70 for a strong effect. In addition to changes in PTSD symptomatology, secondary outcomes will include functional changes related to PTSD, such as quality of life, cognition, and sleep quality, as well as symptoms of commonly reported diagnostic comorbidities of PTSD like major depressive disorder and anxiety disorders.

\section{Study Identification and Selection}

Independent raters will be trained to evaluate studies against eligibility criteria. Studies will be included if they contain continuous PTSD evaluation data collected at the pre- and postintervention stages via validated measures. For the pharmacotherapy group, selection will include a baseline assessment of symptom severity for evaluation of treatment effectiveness followed by the administration of a psychotropic medication. For the psychotherapy group, selection will include a baseline evaluation followed by the administration of a psychologically based treatment. Study reviews are conducted on SWIFT-Active Screener (Sciome), a web-based collaborative screening software for systematic reviews [47]. The reviews will be completed by 8 raters (TL, AB, KS, YL, IK, JS, BJ, and EK). Any disagreements will be resolved through group discussion to reach mutual consensus, led by the first author.

\section{Data Extraction}

From each study, the following data will be extracted: sample size; means and SDs of PTSD scores pre- and post- or mean difference and $P$ values; means and SDs of secondary outcome scores pre- and post or mean difference and $P$ value (if available); pre- and postcorrelations; type of intervention; moderator variables (if available); clinical characteristics; treatment characteristics; and study characteristics.

Missing data will be handled through author contact. A designated member of the research team will email the corresponding authors or research leads for missing data. A follow-up email will be sent after 1 week over a 2-week response window. All data extracted and received will be recorded via Smartsheet (Smartsheet Inc) and exported to R (R Foundation for Statistical Computing) and Comprehensive Meta-Analysis software (Biostat Inc) for data analysis.

\section{Strategy for Data Synthesis and Meta-analyses}

Using Cochrane's guide as a framework for data synthesis, the proposed meta-analysis will seek a minimum of 15 studies to be included for overall analysis, and a minimum of 4 studies to be included for subgroup analyses. For each study, pre- and postintervention means and SDs, along with sample size, will be used to calculate effect sizes. Pre- and postintervention correlations will be calculated based on known data and entered for analysis. For studies without pre- and postintervention data, differences between means, paired-group $P$ values, and directions of effects found will be used as alternative methods to calculate effect sizes. Data will be analyzed using Comprehensive Meta-Analysis software [48] and the metafor $\mathrm{R}$ package [49].

The main analyses of the meta-analysis will comprise a multilevel meta-analytic approach to examine dependency among effect sizes of studies, including overall effects, between-study effects, and within-study effects. Overall analysis will compare group-aggregated effects of psychotherapy with group-aggregated effects of pharmacotherapy. Subgroup analysis will be used to examine the moderating role of clinical 
characteristics (eg, presence and absence of comorbid disorders, PTSD symptom clusters, trauma exposure type, and lifetime diagnosis), treatment characteristics (eg, treatment approach, length, fidelity, and study rigor), and study characteristics (eg, participant demographics, PTSD measurements used, and operationalizations of PTSD). Finally, publication bias will be explored via the visual inspection of funnel plots, the 3-level Egger regression test, the trim-and-fill method, and Orwin fail-safe $\mathrm{N}$.

\section{Systematic Review and Risk-of-Bias (Quality) Assessment}

The systematic review portion of the proposed review will examine intervention fidelity and study rigor. Methods of quality assessment will take into consideration both the quality of studies reported as well as the fidelity of intervention design and delivery. Assessment of fidelity will follow existing frameworks and include benchmarks of design, delivery, receipt, and enactment [50]. Assessment of study rigor will include benchmarks of research design, participant selection, and appropriateness of statistical analysis. Finally, Cochrane's guide to GRADE (Grading of Recommendations, Assessment, Development and Evaluations) assessment will be applied to evaluate the certainty of evidence found within the proposed meta-analysis [51].

\section{Results}

The literature search was completed on April 14, 2021. Following the removal of duplicates using the synthesisr $\mathrm{R}$ package, 12,002 articles were retained for initial title and abstract review. As of July 2021, title and abstract screening has been completed, with 1469 out of 12,002 (12.23\%) studies included for full-text review. The PRISMA flow diagram is shown in Figure 1 [52]. Initial interrater reliability for the title and abstract review was $93.7 \%$ (761/12,002 conflicts, 6.34\%). Full review is expected to be completed in the summer of 2021, with initial results expected for publication by early winter of 2021.

Figure 1. PRISMA (Preferred Reporting Items for Systematic Reviews and Meta-Analyses) flow diagram. *PsycINFO-OVID (n=5050); MEDLINE-OVID $(\mathrm{n}=3978)$; EMBASE-OVID ( $\mathrm{n}=5631)$; CINAHL $(\mathrm{n}=5033)$; ProQuest Dissertation \& Theses $(\mathrm{n}=91)$.

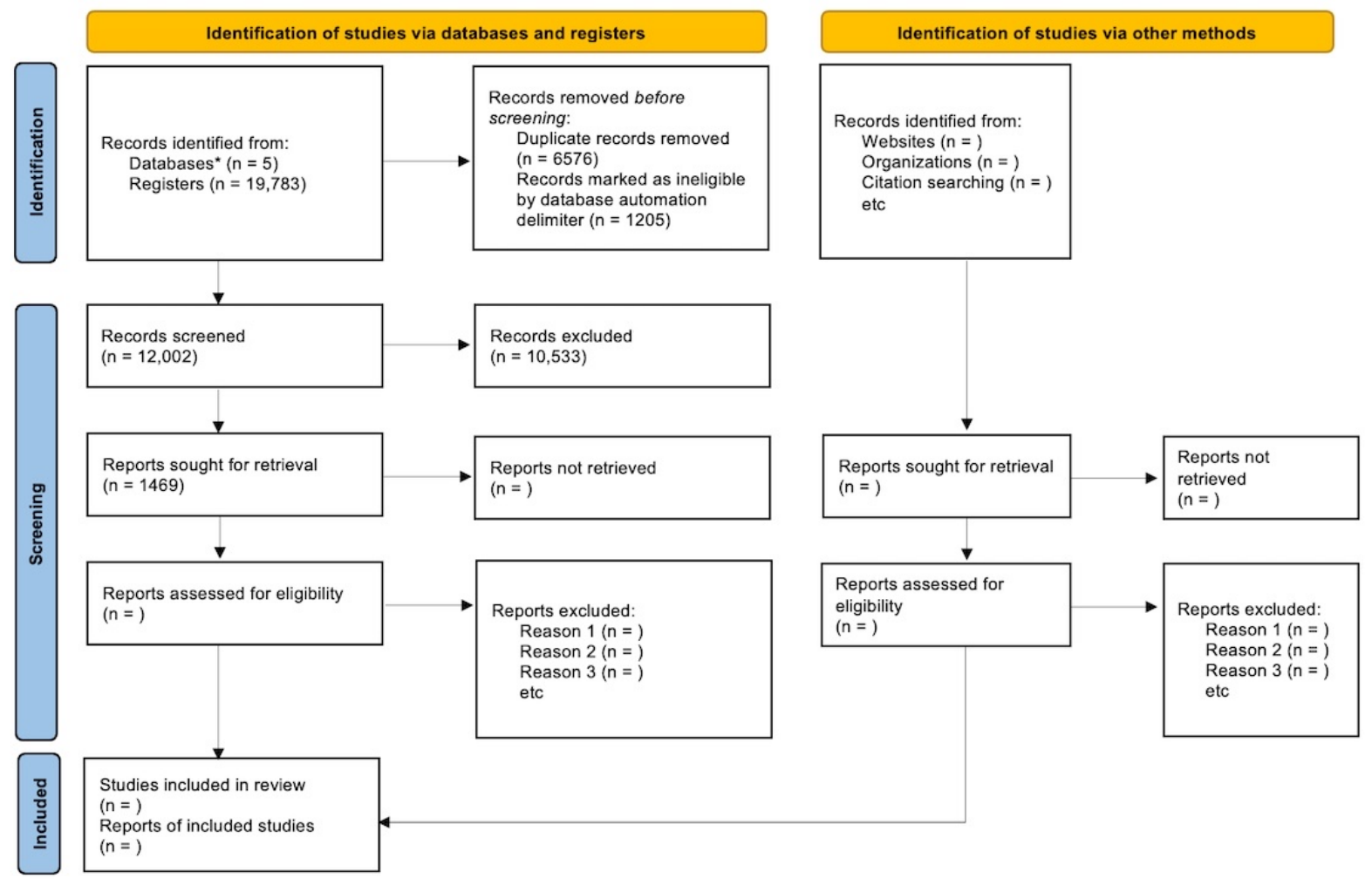

\section{Discussion}

This paper describes the protocol for a meta-analysis and systematic review of the literature on the effectiveness of existing treatment approaches for military-related PTSD. The review will address gaps in the literature, including complexities of the clinical characteristics of PTSD, approaches of and diversities in implementing treatments, and population characteristics that may influence treatment outcomes. This comprehensive review aims to broadly substantiate evidence of PTSD treatment effectiveness to advance consensus guidelines for the treatment of military-related PTSD. The outcomes of this review will serve as a database of available evidence on the treatment of PTSD in military and veteran populations and begin to examine unanswered questions related to treating military-related PTSD. 


\section{Acknowledgments}

The research team would like to thank Yarden Levy, Ilyana Kocha, Jennifer Shatsky, Brittni Jackson, Eliza Khan, Jay Ding, Suriya Ragu, and Samdarsh Saroya for their assistance in this project. This research is not supported by external funding.

\section{Conflicts of Interest}

None declared.

\section{References}

1. Bryant R. Post-traumatic stress disorder: a state-of-the-art review of evidence and challenges. World Psychiatry 2019 Oct;18(3):259-269 [FREE Full text] [doi: 10.1002/wps.20656] [Medline: 31496089]

2. Brunet A, Monson E, Liu A, Fikretoglu D. Trauma Exposure and Posttraumatic Stress Disorder in the Canadian Military. Can J Psychiatry 2015 Nov;60(11):488-496 [FREE Full text] [doi: 10.1177/070674371506001104] [Medline: 26720506]

3. Müller J, Ganeshamoorthy S, Myers J. Risk factors associated with posttraumatic stress disorder in US veterans: A cohort study. PLoS One 2017;12(7):e0181647 [FREE Full text] [doi: 10.1371/journal.pone.0181647] [Medline: 28742837]

4. Reisman M. PTSD Treatment for Veterans: What's Working, What's New, and What's Next. P T 2016 Oct;41(10):623-634 [FREE Full text] [Medline: 27757001]

5. Lofgreen A, Carroll KK, Dugan SA, Karnik NS. An Overview of Sexual Trauma in the U.S. Military. Focus (Am Psychiatr Publ) 2017 Oct;15(4):411-419 [FREE Full text] [doi: 10.1176/appi.focus.20170024] [Medline: $\underline{31975872]}$

6. Nazarov A, Fikretoglu D, Liu A, Thompson M, Zamorski MA. Greater prevalence of post-traumatic stress disorder and depression in deployed Canadian Armed Forces personnel at risk for moral injury. Acta Psychiatr Scand 2018 Apr;137(4):342-354 [FREE Full text] [doi: 10.1111/acps.12866] [Medline: 29504125]

7. Schoenfeld F, Marmar CR, Neylan TC. Current concepts in pharmacotherapy for posttraumatic stress disorder. Psychiatr Serv 2004 May;55(5):519-531 [ [FREE Full text] [doi: 10.1176/appi.ps.55.5.519] [Medline: 15128960]

8. Benedek D, Friedman M, Zatzick D, Ursano R. Guideline Watch (March 2009): Practice Guideline for the Treatment of Patients with Acute Stress Disorder and Posttraumatic Stress Disorder. FOC 2009 Jan;7(2):204-213 [FREE Full text] [doi: 10.1176/foc.7.2.foc204]

9. Straud C, Siev J, Messer S, Zalta AK. Examining military population and trauma type as moderators of treatment outcome for first-line psychotherapies for PTSD: A meta-analysis. J Anxiety Disord 2019 Oct;67:102133 [FREE Full text] [doi: 10.1016/j.janxdis.2019.102133] [Medline: 31472332]

10. Coventry PA, Meader N, Melton H, Temple M, Dale H, Wright K, et al. Psychological and pharmacological interventions for posttraumatic stress disorder and comorbid mental health problems following complex traumatic events: Systematic review and component network meta-analysis. PLoS Med 2020 Aug 19;17(8):e1003262 [FREE Full text] [doi: 10.1371/journal.pmed.1003262] [Medline: 32813696]

11. Thompson J, VanTil L, Zamorski M, Garber B, Dursun S, Fikretoglu D, et al. Mental health of Canadian Armed Forces Veterans: review of population studies. J Mil Veteran Fam Health 2016 Apr;2(1):70-86 [FREE Full text] [doi: 10.3138/jmvfh.3258]

12. Holmes R, Snape I. Effectiveness of treatment of Veterans with PTSD: A critical review. J Exp Psychol 2019;22:3-14 [FREE Full text]

13. Metcalf O, Stone C, Hinton M, O'Donnell M, Hopwood M, McFarlane A, et al. Treatment augmentation for posttraumatic stress disorder: A systematic review. Clinical Psychology: Science and Practice 2020 Mar;27(1) [FREE Full text] [doi: $10.1037 / \mathrm{h} 0101758]$

14. Varker T, Kartal D, Watson L, Freijah I, O'Donnell M, Forbes D, et al. Defining response and nonresponse to posttraumatic stress disorder treatments: A systematic review. Clinical Psychology: Science and Practice 2020 Dec;27(4) [FREE Full text] [doi: $\underline{10.1037 / \mathrm{h} 0101781]}$

15. Resick P, Monson CM, Chard KM. Cognitive processing therapy for PTSD: A comprehensive manual. New York, NY: Guilford Press; 2016.

16. de Arellano MAR, Lyman DR, Jobe-Shields L, George P, Dougherty RH, Daniels AS, et al. Trauma-focused cognitive-behavioral therapy for children and adolescents: assessing the evidence. Psychiatr Serv 2014 May 01;65(5):591-602 [FREE Full text] [doi: 10.1176/appi.ps.201300255] [Medline: 24638076]

17. Foa EB, Hembree EA, Rothbaum BO. Prolonged Exposure Therapy for PTSD: Emotional Processing of Traumatic Experiences, Therapist Guide (2 ed). Oxford, UK: Oxford University Press; 2019.

18. Shapiro F. The Role of Eye Movement Desensitization and Reprocessing (EMDR) Therapy in Medicine: Addressing the Psychological and Physical Symptoms Stemming from Adverse Life Experience. TPJ 2014;18(1):71-77 [FREE Full text] [doi: $10.7812 / \mathrm{tpp} / 13-098]$

19. PTSD Treatment Basics. US Department of Veteran Affairs. 2020. URL: https://www.ptsd.va.gov/understand tx/tx basics. asp [accessed 2021-04-14]

20. Watkins L, Sprang KR, Rothbaum BO. Treating PTSD: A Review of Evidence-Based Psychotherapy Interventions. Front Behav Neurosci 2018;12:258 [FRE Full text] [doi: 10.3389/fnbeh.2018.00258] [Medline: $\underline{30450043}$ ] 
21. Morland L, Hynes AK, Mackintosh MA, Resick PA, Chard KM. Group cognitive processing therapy delivered to veterans via telehealth: a pilot cohort. J Trauma Stress 2011 Aug;24(4):465-469 [FREE Full text] [doi: 10.1002/jts.20661] [Medline: 21793047]

22. Bleiberg K, Markowitz JC. Interpersonal Psychotherapy for PTSD: Treating Trauma without Exposure. J Psychother Integr 2019 Mar;29(1):15-22 [FREE Full text] [doi: 10.1037/int0000113] [Medline: $\underline{\text { 31534308] }}$

23. Pohar R, Argáez C. Acceptance and Commitment Therapy for Post-Traumatic Stress Disorder, Anxiety, and Depression: A Review of Clinical Effectiveness. Canadian Agency for Drugs and Technologies in Health. 2017 Aug 28. URL: https:/ /www.ncbi.nlm.nih.gov/books/NBK525684/ [accessed 2021-10-18]

24. Jeffreys M. Clinician's Guide to Medications for PTSD. US Department of Veterans Affairs. 2021 Mar 19. URL: https:/ /www.ptsd.va.gov/professional/treat/txessentials/clinician_guide_meds.asp\#symptoms [accessed 2021-04-14]

25. Lavano A, Guzzi G, Della Torre A, Lavano SM, Tiriolo R, Volpentesta G. DBS in Treatment of Post-Traumatic Stress Disorder. Brain Sci 2018 Jan 20;8(1):NA [FREE Full text] [doi: 10.3390/brainsci8010018] [Medline: 29361705]

26. Kan RLD, Zhang BBB, Zhang JJQ, Kranz GS. Non-invasive brain stimulation for posttraumatic stress disorder: a systematic review and meta-analysis. Transl Psychiatry 2020 May 28;10(1):168 [FREE Full text] [doi: 10.1038/s41398-020-0851-5] [Medline: 32467579 ]

27. Fragedakis T, Toriello P. The Development and Experience of Combat-Related PTSD: A Demand for Neurofeedback as an Effective Form of Treatment. J Couns Dev 2014 Sep 10;92(4):481-488 [FREE Full text] [doi:

10.1002/j.1556-6676.2014.00174.x ]

28. Monson C, Fredman SJ, Macdonald A, Pukay-Martin ND, Resick PA, Schnurr PP. Effect of cognitive-behavioral couple therapy for PTSD: a randomized controlled trial. JAMA 2012 Aug 15;308(7):700-709 [FREE Full text] [doi: 10.1001/jama.2012.9307] [Medline: 22893167]

29. O'Haire ME, Guérin NA, Kirkham AC. Animal-Assisted Intervention for trauma: a systematic literature review. Front Psychol 2015;6:1121 [FREE Full text] [doi: 10.3389/fpsyg.2015.01121] [Medline: 26300817]

30. Cushing R, Braun KL, Alden C-Iayt SW, Katz AR. Military-Tailored Yoga for Veterans with Post-traumatic Stress Disorder. Mil Med 2018 May 01;183(5-6):e223-e231 [FREE Full text] [doi: 10.1093/milmed/usx071] [Medline: 29415222]

31. Flory J. Comorbidity between post-traumatic stress disorder and major depressive disorder: alternative explanations and treatment considerations. Dialogues Clin Neurosci 2015 Jul;17(2):141-150 [FREE Full text] [doi:

10.31887/dens.2015.17.2/jflory]

32. Mithoefer M, Mithoefer A, Feduccia A, Jerome L, Wagner M, Wymer J, et al. 3,4-methylenedioxymethamphetamine (MDMA)-assisted psychotherapy for post-traumatic stress disorder in military veterans, firefighters, and police officers: a randomised, double-blind, dose-response, phase 2 clinical trial. The Lancet Psychiatry 2018 Jun;5(6):486-497 [FREE Full text] [doi: 10.1016/s2215-0366(18)30135-4]

33. Jones C, Smith-MacDonald L, Miguel-Cruz A, Pike A, van Gelderen M, Lentz L, et al. Virtual Reality-Based Treatment for Military Members and Veterans With Combat-Related Posttraumatic Stress Disorder: Protocol for a Multimodular Motion-Assisted Memory Desensitization and Reconsolidation Randomized Controlled Trial. JMIR Res Protoc 2020 Oct 29;9(10):e20620 [FREE Full text] [doi: 10.2196/20620] [Medline: 33118957]

34. Stewart C, Wrobel TA. Evaluation of the efficacy of pharmacotherapy and psychotherapy in treatment of combat-related post-traumatic stress disorder: a meta-analytic review of outcome studies. Mil Med 2009 May;174(5):460-469 [FREE Full text] [doi: 10.7205/milmed-d-04-1507] [Medline: 20731275]

35. Hoskins MD, Bridges J, Sinnerton R, Nakamura A, Underwood JFG, Slater A, et al. Pharmacological therapy for post-traumatic stress disorder: a systematic review and meta-analysis of monotherapy, augmentation and head-to-head approaches. European Journal of Psychotraumatology 2021 Jan 26;12(1):1802920 [FREE Full text] [doi: $10.1080 / 20008198.2020 .1802920]$

36. Sayer N, Wiltsey-Stirman S, Rosen CS, Bernardy NC, Spoont MR, Kehle-Forbes SM, et al. Investigation of Therapist Effects on Patient Engagement in Evidence-Based Psychotherapies for Posttraumatic Stress Disorder in the Veterans Health Administration. J Trauma Stress 2021 May 28:NA [FREE Full text] [doi: 10.1002/jts.22679] [Medline: 34048602]

37. Liu JJW, Nazarov A, Easterbrook B, Plouffe R, Richardson JD. The effectiveness of pharmacotherapy versus psychotherapy for treating post-traumatic stress disorder in military populations: a meta-analysis. PROSPERO. 2021 Apr 23. URL: https:/ /www.crd.york.ac.uk/prospero/display_record.php?ID=CRD42021245754 [accessed 2021-04-23]

38. Weathers F, Blake DD, Schnurr PP, Kaloupek DG, Marx BP, Keane TM. Clinician-Administered PTSD Scale for DSM-5 (CAPS-5). US Department of Veterans Affairs. 2013. URL: https://www.ptsd.va.gov/professional/assessment/adult-int/ caps.asp [accessed 2021-04-14]

39. Weathers FW, Huska JA, Keane TM. PCL-M for DSM-IV. Boston, MA: National Center for PTSD - Behavioral Science Division; 1991.

40. Weathers FW, Litz BT, Keane TM, Palmieri PA, Marx BP, Schnurr PP. The PTSD Checklist for DSM-5 (PCL-5). US Department of Veterans Affairs/National Center for PTSD. 2013. URL: https://www.ptsd.va.gov/professional/assessment/ adult-sr/ptsd-checklist.asp [accessed 2021-04-14] 
41. Prins A, Bovin MJ, Smolenski DJ, Marx BP, Kimerling R, Jenkins-Guarnieri MA, et al. The Primary Care PTSD Screen for DSM-5 (PC-PTSD-5): Development and Evaluation Within a Veteran Primary Care Sample. J Gen Intern Med 2016 Oct 11;31(10):1206-1211 [FREE Full text] [doi: 10.1007/s11606-016-3703-5] [Medline: 27170304]

42. Wolf EJ, Mitchell KS, Sadeh N, Hein C, Fuhrman I, Pietrzak RH, et al. The Dissociative Subtype of PTSD Scale: Initial Evaluation in a National Sample of Trauma-Exposed Veterans. Assessment 2017 Jun 23;24(4):503-516 [FREE Full text] [doi: 10.1177/1073191115615212] [Medline: 26603115]

43. Foa EB, McLean CP, Zang Y, Zhong J, Powers MB, Kauffman BY, et al. Psychometric properties of the Posttraumatic Diagnostic Scale for DSM-5 (PDS-5). Psychol Assess 2016 Oct;28(10):1166-1171. [doi: 10.1037/pas0000258] [Medline: 26691504]

44. Foa EB, McLean CP, Zang Y, Zhong J, Rauch S, Porter K, et al. Psychometric properties of the Posttraumatic Stress Disorder Symptom Scale Interview for DSM-5 (PSSI-5). Psychol Assess 2016 Oct;28(10):1159-1165. [doi:

10.1037/pas0000259] [Medline: 26691507]

45. Borenstein M, Hedges LV, Higgins JPT, Rothstein HR. A basic introduction to fixed-effect and random-effects models for meta-analysis. Res Synth Methods 2010 Apr;1(2):97-111 [FREE Full text] [doi: 10.1002/jrsm.12] [Medline: 26061376]

46. Ferguson C. An effect size primer: A guide for clinicians and researchers. Professional Psychology: Research and Practice 2009 Oct;40(5):532-538 [FREE Full text] [doi: 10.1037/a0015808]

47. Howard BE, Phillips J, Tandon A, Maharana A, Elmore R, Mav D, et al. SWIFT-Active Screener: Accelerated document screening through active learning and integrated recall estimation. Environ Int 2020 May; 138:105623 [FREE Full text] [doi: 10.1016/j.envint.2020.105623] [Medline: 32203803]

48. Borenstein M, Hedges L, Higgins JPT, Rothstein HR. Comprehensive Meta-Analysis (version 2.2.027). Biostat Inc. 2005. URL: https://www.meta-analysis.com [accessed 2021-10-18]

49. Viechtbauer W. Conducting Meta-Analyses in with the Package. J Stat Soft 2010;36(3) [FREE Full text] [doi: 10.18637/jss.v036.i03]

50. Fikretoglu D, Easterbrook B, Nazarov A. Fidelity in workplace mental health intervention research: A narrative review. Work \& Stress 2021 Jun 14:1-24. [doi: 10.1080/02678373.2021.1936286]

51. Schünemann H, Brozek J, Guyatt G, Oxman A. Handbook for grading the quality of evidence and the strength of recommendations using the GRADE approach. The GRADE Working Group. 2013. URL: http://www.gradeworkinggroup.org/ [accessed 2021-04-14]

52. Page MJ, McKenzie JE, Bossuyt PM, Boutron I, Hoffmann TC, Mulrow CD, et al. The PRISMA 2020 statement: an updated guideline for reporting systematic reviews. BMJ 2021 Mar 29;372:n71 [FREE Full text] [doi: 10.1136/bmj.n71] [Medline: 33782057]

\section{Abbreviations \\ DSM: Diagnostic and Statistical Manual of Mental Disorders \\ GRADE: Grading of Recommendations, Assessment, Development and Evaluations \\ PRISMA: Preferred Reporting Items for Systematic Reviews and Meta-Analyses \\ PTSD: posttraumatic stress disorder}

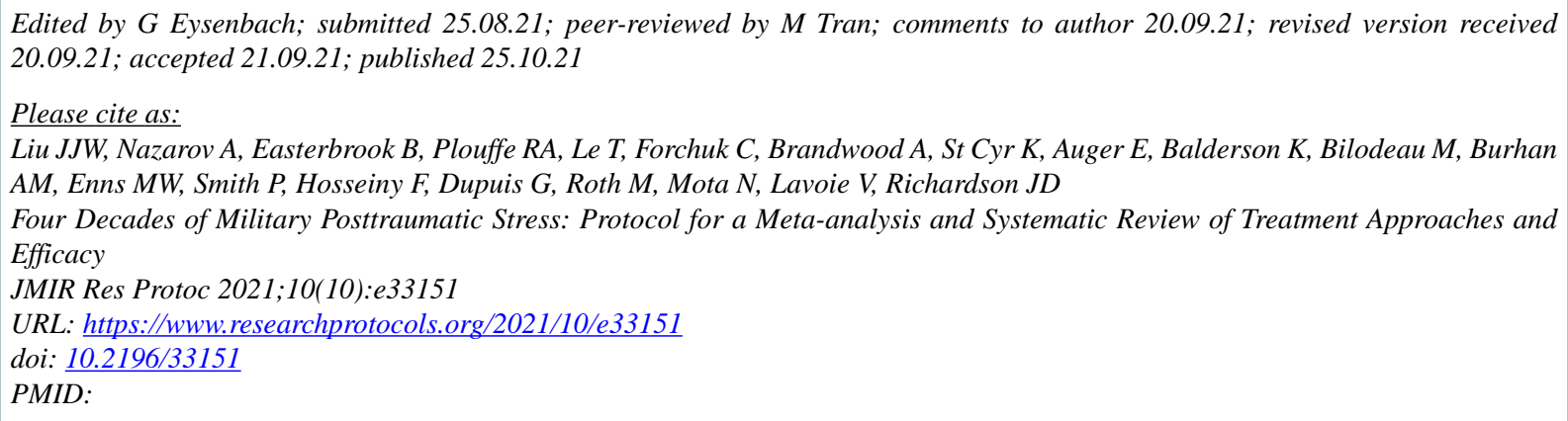

(CJenny J W Liu, Anthony Nazarov, Bethany Easterbrook, Rachel A Plouffe, Tri Le, Callista Forchuk, Alec Brandwood, Kate St Cyr, Edouard Auger, Ken Balderson, Mathieu Bilodeau, Amer M Burhan, Murray W Enns, Patrick Smith, Fardous Hosseiny, Gabrielle Dupuis, Maya Roth, Natalie Mota, Vicky Lavoie, J Don Richardson. Originally published in JMIR Research Protocols (https://www.researchprotocols.org), 25.10.2021. This is an open-access article distributed under the terms of the Creative Commons Attribution License (https://creativecommons.org/licenses/by/4.0/), which permits unrestricted use, distribution, and 
reproduction in any medium, provided the original work, first published in JMIR Research Protocols, is properly cited. The complete bibliographic information, a link to the original publication on https://www.researchprotocols.org, as well as this copyright and license information must be included. 